\title{
Workload of general practitioners before and after the new contract
}

\author{
David Hannay, Tim Usherwood, Maria Platts
}

\begin{abstract}
Objective-To assess changes in general practitioners' workload associated with the new contract introduced in April 1990.
\end{abstract}

Design-Weekly workload diary completed during four weeks in February-March 1990 and during the same period in 1991.

Setting-Sheffield, United Kingdom.

Subjects-All 300 general practitioners on Sheffield Family Health Services Authority list as principals in 1990 and 1991.

Main outcome measures-Mean number of hours worked per week, number of patients seen each week, and mean time spent per patient.

Results-181 (60\%) general practitioners responded in 1990 and $163(54 \%)$ in 1991 . Of these, $18(10 \%)$ were not working in 1990 and $14(7 \%)$ in 1991. General medical service work increased during a "normal working week" from a mean of 38.6 hours a week in 1990 to 40.6 hours in 1991, and non-general medical service work decreased from 5.4 hours a week to 4.5 hours. Hours spent on call were similar before and after the contract. For the 99 general practitioners who responded in both years, time spent on general medical service duties increased significantly $(40.4 \mathrm{~h}$ in $1990 v 42.6 \mathrm{~h}$ in 1991; $\mathbf{p}=0.033$ ), mainly due to more time being spent in clinics. Significantly more patients were being seen in clinics $(9 v 14 ; \mathrm{p}=0.001)$; the average time spent per patient remained at about $81 / 2$ minutes during surgeries and 16 minutes for a home visit, and rose from 13 to 14 minutes for patients seen in clinics. The time spent on practice administration fell but not significantly.

Conclusion-Since the new contract there has been a significant increase in general medical services work, mainly due to more patients being seen in clinics, with no reduction in the time spent per patient.

\section{Introduction}

The new contract for general practice was published in the wake of the government's white paper Working for Patients' ${ }^{1}$ and came into force on 1 April 1990. The reforms were intended to change the way in which general practitioners worked with an emphasis on accountability, competition, prevention, and value for money. ${ }^{2}$

Several studies of general practitioner workload were made before the new contract was published, notably the report prepared for the doctors and dentists review body by the Department of Health and Social Security and the General Medical Services Committee in 1985-6. ${ }^{4}$ This survey was repeated in 1989-90, the year preceding the introduction of the contract in April 1990.5 Later that year the GMSC commissioned management consultants to research the workload of general practitioners after the contract, but this was abandoned due to lack of response.
We assessed the effect of the new contract on workload by surveying the same group of general practitioners for one month before the new contract came into effect and again one year later.

\section{Subjects and methods}

All 300 general practitioner principals on Sheffield Family Health Services Authority list were sent a weekly workload diary during the four weeks 18 February to 18 March 1990 and again a year later during the equivalent four weeks 17 February to 17 March 1991. The diary covered seven days and was sent to 75 different doctors in each of the four weeks.

The diary was designed to cover categories of general medical services duties and non-general medica services duties which were comparable with those used in the 1985-6 workload study. ${ }^{4}$ It also included details of hours on call and the numbers of patients seen each day. Time was recorded to the nearest half hour on a daily basis from 7 pm one day until $7 \mathrm{pm}$ the next. After a pilot study responders were encouraged to complete the diary retrospectively for each 24 hour period as soon after $7 \mathrm{pm}$ as possible, rather than continuously recording every half hour as for the government GMSC surveys. ${ }^{45}$

The daily results for each respondent were aggregated to weekly totals before analysis. These data were analysed by the statistical package SPSS-PC. Most frequency distributions were highly skewed, so comparisons between those doctors who responded in both 1990 and 1991 were made with the Wilcoxon signed rank test. The null hypothesis was rejected if the test statistic exceeded $0 \cdot 05$. No details of individual doctors were collected apart from their workload. Responses were identified by only a code number and no names appeared on the forms to ensure confidentiality.

The survey was supported by the local medical committee, and in both years was preceded by a letter to all Sheffield general practitioners to encourage a high response rate and accurate recording. The weekly diaries with a covering letter and instructions were distributed a week in advance of the recording week, and all general practitioners were sent a follow up letter at the end of the four weeks.

\section{Results}

Three hundred general practitioners were on Sheffield Family Health Services Authority list for the four weeks in both 1990 and 1991, although they were not all the same doctors. Workload diaries were returned by 181 general practitioners $(60 \%)$ in 1990 and 163 $(54 \%)$ in 1991.

Eighteen doctors were not working during the study period in 1990 and 14 were not working in 1991, mainly because of holidays or illness (table I). Between one quarter and a third of general practitioners were working seven days a week, and those working in both
Correspondence to: Professor Hannay. 
years had an average of $1 \cdot 3$ days off in seven. Ninety nine doctors who completed diaries were working in both 1990 and 1991 .

Table II compares the average normal working week for the 163 respondents in 1990 who were working during the study period with that for the 149 respondents who were working in 1991. There was an increase in total general medical services work mainly due to more time being spent in clinics, but more time was also being spent in patients' homes and on teaching. Although time spent discussing cases and on paperwork increased, time spent on practice administration fell. The increase in other general medical service activities was mainly due to minor surgery. Less time was spent on non-general medical service work after the new contract, largely because of a decrease in time spent doing hospital clinical assistantships. Overall there was an increase of just over one hour a week in the average total number of hours worked.

Both the amount and the range of activities undertaken by doctors varied considerably in both years. The proportion who taught rose from $32 \%$ to $42 \%$ over the two years, and the percentage undertaking other general medical service activities such as minor surgery increased from $12 \%$ to $22 \%$. The proportion of doctors attending courses fell from $47 \%$ to $31 \%$, and the proportion engaged in clinical non-general medical service work such as clinical assistantships fell from $50 \%$ to $41 \%$.

Although there was little overall change in the total number of hours on call, there was an increasing tendency for out of hours on call to be shared with other practices (table III). The proportion of doctors on call for another practice as well as their own increased from $9 \%$ to $15 \%$ during working hours and from $12 \%$ to $18 \%$ out of hours and during weekends. The proportion of doctors on call for only their own practice out of hours fell from $69 \%$ to $53 \%$. Both before and after the new contract only $4 \%$ of doctors were working for the deputising services, and the proportion of general practitioners who were on call for their own practices at sometime during working hours remained the same at $91 \%$.

Table IV compares the average number of patients seen per week and the time spent per patient in 1990 and 1991. Activity varied considerably, with a maximum of 324 and 347 patients being seen overall in 1990 and 1991 respectively. The maximum number of home visits by a doctor was 100 (recorded in 1990), and the maximum number of clinic patients seen was also 100 (recorded in 1991). The average time spent with patients was calculated from the total time spent with patients and the numbers of patients seen. The minimum mean time spent per patient in surgery was $3 \cdot 1$ minutes (one doctor in 1991) and the maximum 24.5 minutes (one doctor in 1990). The maximum average time spent per patient was one hour in clinics and 48 minutes for house calls.

Because of the large variations in work patterns among doctors, as indicated by the size of the standard deviations, it is difficult to know how much of the differences was caused by there being different groups of respondents in the two years. To minimise these differences we also compared workload for the same doctors who responded and were working in both 1990 and 1991 (tables II-IV). Total general medical service work increased significantly, mainly because of more time being spent in clinics. Significantly more patients were being seen in clinics after the new contract than before, and slightly more time was being spent per patient (table IV). Significantly more time was spent on other general medical service activities, much of which was accounted for by minor surgery. The amount of non-general medical service work fell, mainly due to less time being spent on clinical work in assistant grades in hospital. The average number of hours on call before and after the contract did not change

TABLE II - Mean (SD) weekly working hours in 1990 and 1991 for doctors who were working during study

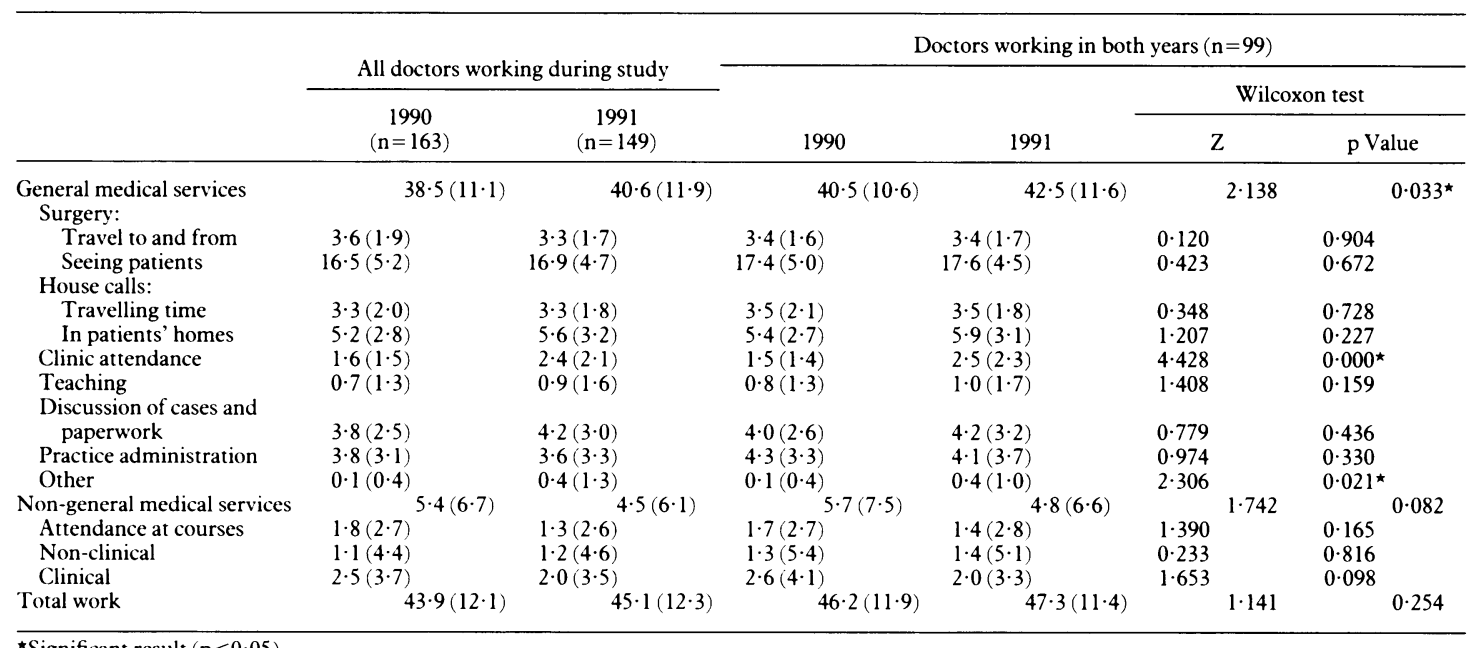

* Significant result $(\mathrm{p}<0 \cdot 05)$

Mean numbers of hours rounded to one decimal place and Wilcoxon test results rounded to three places of decimals

TABLE III - Mean (SD) hours spent on call during an average week in 1990 and 1991

\begin{tabular}{|c|c|c|c|c|c|c|}
\hline & & & \multicolumn{4}{|c|}{ Doctors working in both years $(n=99)$} \\
\hline & \multicolumn{2}{|c|}{ All doctors working during study } & \multirow[b]{2}{*}{1990} & \multirow[b]{2}{*}{1991} & \multicolumn{2}{|c|}{ Wilcoxon test } \\
\hline & $1990(n=163)$ & $1991(n=149)$ & & & $\mathrm{Z}$ & $\mathrm{p}$ Value \\
\hline \multicolumn{7}{|l|}{ During working day: } \\
\hline Own practice only & $25 \cdot 8(21 \cdot 7)$ & $26 \cdot 1(22 \cdot 7)$ & $27 \cdot 1(20 \cdot 7)$ & $27 \cdot 1(22 \cdot 9)$ & $0 \cdot 206$ & 0.837 \\
\hline Own and other practices & $1 \cdot 1(4 \cdot 8)$ & $1 \cdot 8(6 \cdot 4)$ & $1 \cdot 4(5 \cdot 6)$ & $1 \cdot 5(5 \cdot 2)$ & $0 \cdot 457$ & 0.648 \\
\hline \multicolumn{7}{|l|}{ Out of hours or weekends: } \\
\hline Own practice only & $15 \cdot 4(18 \cdot 8)$ & $14 \cdot 7(22 \cdot 5)$ & $14 \cdot 7(18 \cdot 7)$ & $15 \cdot 6(22 \cdot 4)$ & 0.424 & 0.672 \\
\hline Own and other practices & $2 \cdot 4(9 \cdot 1)$ & $2 \cdot 7(8 \cdot 4)$ & $3.7(11.5)$ & $3 \cdot 0(8 \cdot 6)$ & $0 \cdot 296$ & 0.767 \\
\hline Commercial deputising service & $0 \cdot 3(1 \cdot 3)$ & $0 \cdot 4(2 \cdot 3)$ & $0 \cdot 3(1 \cdot 2)$ & $0 \cdot 4(1 \cdot 8)$ & $0 \cdot 524$ & $0 \cdot 600$ \\
\hline
\end{tabular}

Mean number of hours rounded to one decimal place and Wilcoxon test results rounded to three places of decimals. 


\begin{tabular}{|c|c|c|c|c|c|c|}
\hline & \multirow{2}{*}{\multicolumn{2}{|c|}{ All doctors working during study }} & \multicolumn{4}{|c|}{ Doctors working in both years $(n=99)$} \\
\hline & & & \multirow[b]{2}{*}{1990} & \multirow[b]{2}{*}{1991} & \multicolumn{2}{|c|}{ Wilcoxon test } \\
\hline & $1990(n=163)$ & $1991(n=149)$ & & & $\mathrm{Z}$ & p Value \\
\hline \multicolumn{7}{|c|}{ No of patients seen/week } \\
\hline In surgery & $122(47)$ & $1124(45)$ & $128(39)$ & $129(45)$ & 0.529 & 0.597 \\
\hline At home & $21(13)$ & $21(12)$ & $22(14)$ & $22(11)$ & 0.487 & 0.626 \\
\hline In clinic & $8(10)$ & $13(16)$ & $9(11)$ & $14(17)$ & $3 \cdot 410$ & 0.001 \\
\hline Total & $151(49)$ & $158(58)$ & $159(49)$ & $165(56)$ & $1 \cdot 884$ & $0 \cdot 060^{\star}$ \\
\hline \multicolumn{7}{|c|}{ Time/patient $(\mathrm{min})$ : } \\
\hline In surgery & $8 \cdot 7(2 \cdot 8)$ & $8 \cdot 5(2 \cdot 4)$ & $8 \cdot 5(2 \cdot 6)$ & $8 \cdot 5(2 \cdot 3)$ & 0.044 & 0.965 \\
\hline At home & $16 \cdot 6(6 \cdot 2)$ & $16 \cdot 8(6 \cdot 4)$ & $16 \cdot 2(5 \cdot 5)$ & $16 \cdot 7(6 \cdot 6)$ & 0.226 & 0.821 \\
\hline In clinic & $13 \cdot 8(8 \cdot 1)$ & $14.4(8 \cdot 6)$ & $13 \cdot 0(6 \cdot 7)$ & $14 \cdot 2(8 \cdot 5)$ & 0.403 & 0.687 \\
\hline
\end{tabular}

$\star$ Significant result $(\mathrm{p}<0.05)$

Means rounded to one decimal place and Wilcoxon test results rounded to three places of decimals.

TABLE V-Mean number of hours worked by doctors per week in surveys before and after the contract

\begin{tabular}{|c|c|c|c|c|}
\hline & \multicolumn{3}{|c|}{ Before contract } & \multirow{2}{*}{$\begin{array}{c}\text { After contract } \\
\text { Sheffield } \\
1991 \\
(\mathbf{n}=99)\end{array}$} \\
\hline & $\begin{array}{c}\text { Government/GMSC } \\
1985-6^{+\star} \\
(n=24862)\end{array}$ & $\begin{array}{c}\text { Government/GMSC } \\
1989-90^{\star \star} \\
(\mathrm{n}=26601)\end{array}$ & $\begin{array}{c}\text { Sheffield } \\
1990 \\
(\mathrm{n}=99)\end{array}$ & \\
\hline $\begin{array}{l}\text { General medical service work } \\
\text { Non-general medical service work } \\
\text { Total work }\end{array}$ & $\begin{array}{r}38 \cdot 2 \\
6 \cdot 0 \\
42 \cdot 8\end{array}$ & $\begin{array}{r}40 \cdot 9 \\
6 \cdot 4 \\
46 \cdot 2\end{array}$ & $\begin{array}{r}40 \cdot 5 \\
5 \cdot 7 \\
46 \cdot 2\end{array}$ & $\begin{array}{r}42 \cdot 5 \\
4 \cdot 8 \\
47 \cdot 3\end{array}$ \\
\hline
\end{tabular}

ॠThe sample size shown is for general medical service plus non-general medical service work, but different samples were used to calculate the means for general medical service work and non-general medical service separately, and therefore these means do not sum. significantly, although a greater proportion of doctors were on call for their own and other practices after the new contract than before.

Table V compares workload figures from the present study with those of the two previous government/ GMSC studies in 1985-6 $6^{4}$ and 1989-90.5 Both these surveys were spread over a calendar year with the second study ending on 2 April 1990, just as the new contract came into effect. The results of these surveys are similar to our own results in 1990 , which suggests that the workload changes shown by the Sheffield doctors a year after the new contract would be reflected in a national survey. On average, general practitioners were spending two hours a week more on general medical service work after the new contract and one hour a week less on non-general medical service work, resulting in an overall increase of about one hour in their weekly workload.

\section{Discussion}

The response rates of $60 \%$ in 1990 and $54 \%$ in 1991 are comparable with those for the two government/ GMSC surveys ${ }^{45}$ These two national surveys were based on single weeks throughout a calendar year whereas our study was confined to two four week periods. Nevertheless, a similar proportion of respondents were not working in the 1989-90 government/GMSC survey to the $10 \%$ in our study.

In addition to the normal working week, the government/GMSC surveys calculated workload figures for an "average annual week" by aggregating data from weeks spread over a year for individual doctors, including those not working, on the assumption that others would have been working extra hours to cover absent colleagues. On the same basis the total general medical service and non-general medical service work for an annual average week in our study was 39.5 hours in 1990 and 41.2 hours in 1991. These figures are less than those for the normal working week shown in table II and reflect the fact that doctors working five or more days a week as full time principals comprised about $90 \%$ of those who were working but only about $80 \%$ of all respondents.

The normal working week, as used in this and other studies, ${ }^{6-8}$ is the usual basis for workload estimates, but it includes the minority of doctors who are working part time. Neither the national surveys nor our study distinguished full time principals from those who worked less than full time. The normal working week is therefore misleading in that it underestimates the workload of full time general practitioners. ${ }^{9}$

Even allowing for part time principals, there was considerable variation in doctors' working patterns, particularly for non-general medical service work and hours on call. There were also clear differences in numbers of patients seen, especially in clinics, although less overall variation was seen in the amount of time spent per patient.

The sample size was $7 \cdot 7 \%$ principals in the United Kingdom in the 1985-6 government/GMSC survey ${ }^{4}$ and roughly double that in the $1989-90$ survey. ${ }^{5}$ With 300 general practitioners and a population of about half a million, our survey approximates to a $1 \%$ sample of the United Kingdom. Table V suggests that our nonrandom sample is representative of the workload of general practitioners in the United Kingdom as a whole and that the differences in work patterns we observed would be reflected in a national survey.

We compared the same four week period before and after the new contract in order to control for seasonal variation in workload. The period chosen was between the main season of winter morbidity on the one hand and summer holidays on the other, and the workload recorded in 1990 was very similar to the annual average in the 1989-90 government/GMSC survey (table V). We did not collect details of individual doctors, mainly because this was outside the explicit aims of the study, which concerned only workload. We also felt that collecting such information might have reduced both compliance and confidentiality. We therefore could not compare the characteristics of responders and nonresponders, but again table $\mathrm{V}$ suggests that those who responded in both years were representative of general practitioners overall.

\section{CHANGES IN WORKLOAD}

The increase in time spent in patients' homes may have been because of routine checks on patients over 75 , but the increased time spent on teaching was mainly because more doctors were taking part. This may have been due to medical students in Sheffield being attached for longer to practices since the new contract, which increased payments for teaching. It seems that the differential night visit fee has encouraged practice rotas, with a corresponding reduction in the number of doctors being on call for only their own practices out of hours. This will result in patients being less likely to see their own doctor for an out of hours call.

Contrary to expectations the time spent on practice administration by doctors fell. This may have been due to an increased amount of administration during February and March 1990 in preparation for the new contract, when the mean time of $\mathbf{4} \cdot \mathbf{3}$ hours a week was more than the $2 \cdot 4$ hours recorded in the 1985-6 
government/GMSC survey. The reduction in administration time to $4 \cdot 1$ hours a week in 1991 was almost certainly due to an increase in the number of practice managers, who bear the brunt of the paperwork generated by the new contract.

There was a reduction of about one hour a week in non-general medical service work. Although most of this fall was caused by a drop in the number of clinical assistantships, less time was also spent on courses, perhaps because most doctors had achieved their sessions for the postgraduate education allowance by the time of the survey. Overall, doctors were working on average one hour a week longer after the contract, with no appreciable change in the number of hours on call.

\section{OUT OF HOURS WORK}

The average total number of hours worked per week by the 99 doctors who completed both parts of the survey was 64.6 hours before the new contract and $65 \cdot 9$ hours one year later. The extra time was due to additional general medical service work. The average total number of hours worked per week was calculated by adding the average weekly hours on call out of hours or at weekends (except work for deputising services) to the total weekly average of general medical service and non-general medical service work. A similar calculation from the 1989-90 government/GMSC data gives a total average number of hours worked per week of 71.9 hours. ${ }^{5}$ As the average hours worked per week on general medical service and non-general medical service work in the two studies was the same at $46 \cdot 2$ (table V), the difference between the two estimates of $7 \cdot 3$ hours per week must have been due to differences in time on call out of hours.

There are two possible explanations for the difference in time on call out of hours. Either general practitioners in Sheffield were spending less time on call out of hours than the national average or the basis on which out of hours on call was calculated was not the same in the two studies. The first possibility can be tested by comparing the proportion of claims for night visits paid by family health services authorities to deputies. In the second quarter of 1989 the mean percentage of night visits undertaken by deputies for the 90 authorities in England was $45.6 \%$ with a median of $52.8 \%$ (A Lowy, personal communication). The proportion for Sheffield was $59 \cdot 0 \%$, which corresponds to the 53rd centile of the distribution for England and would not account for the difference of over seven hours between the two studies.

The second explanation is that the method of assessing out of hours on call was different in the two surveys. In the government/GMSC study the average total number of hours was defined as "GMS and NonGMS Duties including on call only." Unfortunately time on call during the working day and time on call out of hours or at weekends cannot be distinguished from the published data. This distinction was made in our study, in which workload diaries were completed retrospectively every 24 hours. By contrast, the government/GMSC diary was completed at half hourly intervals and allowed for the recording of multiple entries. Hours "on call only" could therefore include periods during the working day when no other work was being done, such as mealtimes, or time spent travelling from house calls, whereas these would not have been included in the Sheffield figures for being on call out of hours or at weekends. Differences in the method of recording hours on call only are therefore the most likely explanation of the discrepancy between the two studies.

\section{TIME SPENT PER PATIENT}

The average time spent per patient in surgery was $81 / 2$ minutes, with about twice that for a home visit and an increase from 13 to 14 minutes per patient seen in a clinic. Although more patients are now being seen each week especially in clinics, there is no reduction in the time spent per patient. A year after the new contract general practitioners are working longer hours.

We thank the general practitioners who completed the weekly diary, the family health services authority for circulating the questionnaires, the local medical committee for its support, Kate Thomas and Dr Adam Lowy for valuable comments, and Diane Allen and Marilyn Lidster for secretarial help.

1 Secretaries of State for Health, Wales, Northern Ireland, and Scotland. Workin for patients. London: HMSO, 1989.

2 Health Departments of Great Britain. General practice in the National Health Service. The 1990 contract. London: HMSO, 1989.

3 Thomas K, Birch S, Milner P, Nicholl J, Westlake L, Williams BT. Estimates of general practitioner workload: a review. $\mathcal{F}$ Coll Gen Pract 1989;39: 509-13.

4 Department of Health and Social Security. General medical practitioners workload. A report prepared for the doctors and dentists review body 1985/86. London: DHSS, 1987

5 Department of Health. General medical practitioners' workload survey 1989-90. A report prepared for the doctors and dentists review body. London: $\mathrm{DoH}, 1991$.

Butler JR, Calnan MW. Too many patients? A study of the economy of time and standards of care in general practice. London: Tavistock, 1988.

7 Crombie DL, Fleming DM. Report on practice activity analysis. Birmingham: Birmingham Research Unit, Royal College of General Practitioners, 1987.

Wilkin D, Metcalfe DH. Anatomy of urban general practice. London: Tavistock 1988.

9 Ridsdale L. General practitioners' workload. BM 1990;301:455.

(Accepted 20 December 1991)

\section{ONE HUNDRED YEARS AGO}

A BONESETTER SEVERELY CENSURED.

On February 22nd an inquest was held at the Blaina Police Station, before Mr. W. B. Walford, District Coroner, touching the death of David Thomas Williams, a lad, aged 12 years, who died from injuries received from a fall whilst sliding on the roadway on January 16th. The patient was attended by a qualified medical man, but the father subsequently called in one Davies, described as a bonesetter, who said that both the boy's shoulders were out of place, and immediately operated on the lad. Davies attended the boy four or five times afterwards, until the deceased became very ill. About a fortnight had now passed since the accident, when the father called in Dr. Browne, of Brynmawr, who attended the boy up to the time of his death. The inquest was adjourned for a postmortem examination to be made. At the adjourned inquest the bonesetter, who said that he worked at a quarry as labourer, gave evidence. He said that he found both the lad's shoulders were out of place, and put them back in their proper places. The coroner here cautioned the witness as to the manner in which he had given his evidence. The witness said he heard the bones go back in each shoulder, and the boy was able afterwards to move his arms about quite freely. Dr. W. E. Williams (Abertillery) said, at the request of the coroner, he had, with the assistance of Dr. Sergeant, made a post-mortem examination. He found no external marks or injuries, no traces of injuries to either shoulder, or any sign of dislocation having occurred. He found the spinal cord intensely inflamed, and attributed death to this condition. It was his definite opinion that there had been no dislocation. The jury, after a rather lengthy deliberation, agreed to the following verdict: "The deceased died from inflammation of the spine caused by injuries received from a fall while sliding, and thus accidentally came by his death. The jury consider that the so-called bonesetter, Lloyd Davies, is deserving of gravest censure for interference with the patient, and that the father is also much to blame for neglecting the instructions of the doctor in calling in the bonesetter." (BMF 1892;i:461.) 